\title{
Compassion fatigue in critical care nurses
}

\author{
An integrative review of the literature
}

Jalal Alharbi, BSC, MPhil, Debra Jackson, PhD, FACN, Kim Usher, FACN, FACMHN.

\section{ABSTRACT}

الأهداف : لتقديم تقييم نقدي للأدلة التجريبية الحالية المتعلقة

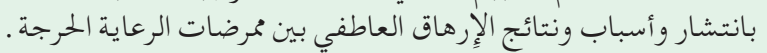

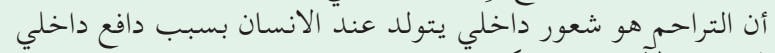

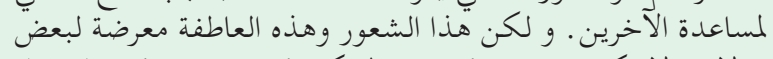

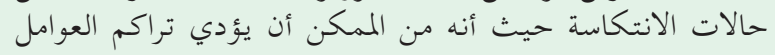
السلبية

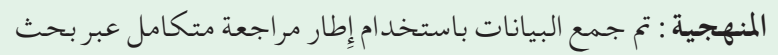

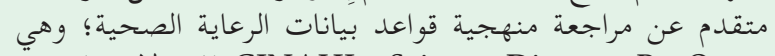

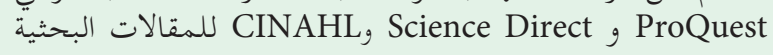

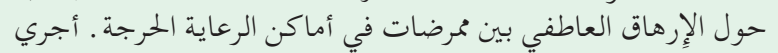

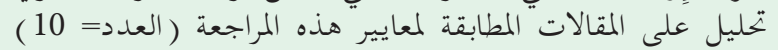

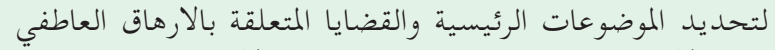

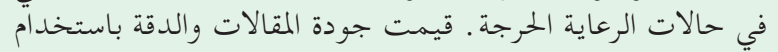

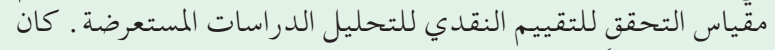

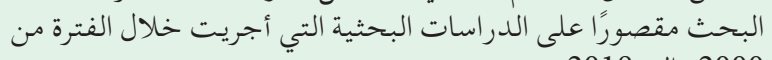

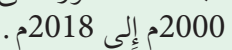

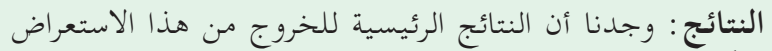

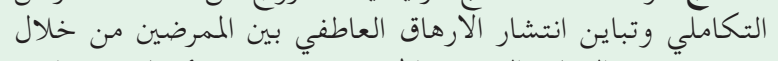

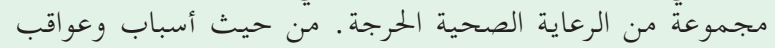

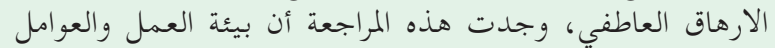

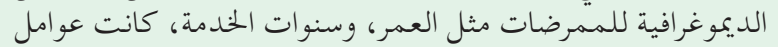

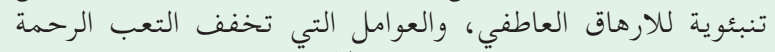

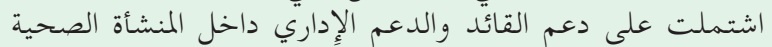

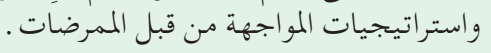

الخلاصة : هناك أدلة غير حاسمة لتحديد تنبؤات الارهاق العاطفي

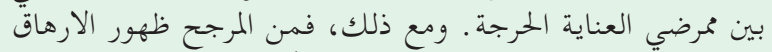

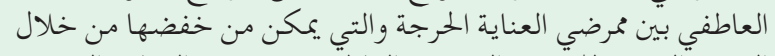

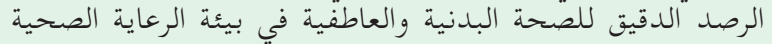

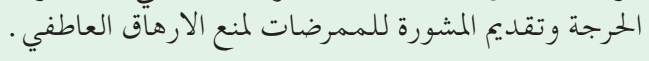

Objectives: To provides a critical evaluation of current empirical evidence related to the prevalence, causes and outcomes of compassion fatigue among critical care nurses. Compassion fatigue is characterized the development of emotional, physical, and/or spiritual exhaustion as a result of working with traumatized individuals.
Methods: Data was collected using an integrated review framework via an advanced search of healthcare databases; namely, ProQuest, Science Direct, and CINAHL for research articles on compassion fatigue among nurses in critical care settings. Analysis was performed on the articles which met the inclusion criteria for this review $(n=10)$ to identify the key themes and issues related to the compassion fatigue in critical care situations. Articles were assessed for quality and rigor using the Critical Appraisal Checklist for Analytical Cross-Sectional Studies. The search was limited to research studies undertaken from 2000 to 2018.

Results: The main findings to emerge from this integrative review was that the prevalence of compassion fatigue among nurses varied across the range of critical care settings. In terms of the causes and consequences of compassion fatigue, this review found work environment and nurse demographics such as age and years of experience, were predictors of compassion fatigue, and the factors mitigating compassion fatigue affects among critical nurse included leader and administrative support within the clinical setting and the coping strategies employed by the nurses.

Conclusion: There is inconclusive evidence to identify unequivocal predictors of compassion fatigue among critical nurses. However, it is likely the onset of compassion fatigue among critical care nurses may be reduced with close monitoring of physical and emotional wellbeing in the critical care environment as well as through the provision of education to nurses to assist with the development of coping strategies to avoid compassion fatigue.

PROSPERO REG. NO: CRD42019123962

Saudi Med J 2019; Vol. 40 (11): 1087-1097 doi: 10.15537/smj.2019.11.24569

From the School of Health (Alharbi, Usher), University of New England, Armidale and from the School of Health (Jackson), University of Technology Sydney, Ultimo, Australia.

Received 25th June 2019. Accepted 13th September 2019.

Address correspondence and reprint request to: Dr. Jalal Alharbi, School of Health, University of New England, Armidale, Australia. E-mail: jalharbi@myune.edu.au

ORCID ID: https://orcid.org/0000-0003-3314-9365 
$\mathrm{C}$ ompassion is a feeling or emotion, which produces an internal drive to help others. ${ }^{1}$ However, an accumulation of the negative drivers that prompt compassion from the individual in any range of contexts (namely the work environment, related to relationships, or from care giving activities) can result in compassion fatigue (CF). ${ }^{2}$ Compassion fatigue is typically understood as emotional, physical, and spiritual exhaustion from "witnessing and absorbing the problems and suffering of others" when working with traumatized individuals. ${ }^{3}$ Although the term CF is often used interchangeably in the literature with 'burnout' and secondary traumatic stress (STS), this paper draws distinctions between the 3 constructs, linking burnout to emotional exhaustion and depersonalization, and considering STS as an outcome of pressure and anxiety. ${ }^{4}$

Compassion fatigue has long been recognized among nurses who provide direct, intimate care to patients. ${ }^{5}$ It may be especially evident among critical care nurses ${ }^{4}$ who care for individuals with life-threatening conditions to which many succumb. In this review paper, critical care nurses are categorized as those providing care to critically ill or unstable patients due to injury, surgery or life-threatening diseases across a diverse range of care settings including intensive care units (ICU) (surgery, medical paediatric ICUs), coronary care units (CCUs), burns units, and trauma centre emergency departments EDs).

Human attachment may become inevitable for critical care nurses working closely with their patients and family members. Therefore, the occurrence of sudden death or major loss may have a negative impact on critical care nurses in the form of an accumulation of negative feelings, which, over time, may contribute to the development of $\mathrm{CF}^{6,7}$ The development of these negative emotions in nurses can result in feelings of helplessness at being unable to halt the deteriorating health of patients and the subsequent heightened feeling of death anxiety. ${ }^{8,9}$ These intense feelings may result in an emotional overextension leading to stress and CF.

Moreover, nursing involves intimate interactions with patients, their families and friends. These close relationships create a sense of empathy which is a key component of compassionate care in the critical care setting. Empathy refers to being able to understand a patient's emotional responses and attribute them to

Disclosure. Authors have no conflict of interests, and the work was not supported or funded by any drug company. what patients are experiencing and what needs emerge because of this experience. ${ }^{10}$ Critical care settings can contribute to CF among nurses because of the severely sick nature of patients, the complexity of their care needs, and the increased likelihood of complications leading to deterioration in the health condition of patients, including death. Some would describe these units as emotionally draining due to the frequent experience of death. ${ }^{4}$

Nurses in critical care units may thus witness human hardship and complex care needs more frequently compared to nurses in other areas of care. Such hardships and complex care needs potentiate the pressures and competing demands experienced by the nurses, thus increasing the need for organisational support to help avoid CF.11 For instance, Goodrich ${ }^{12}$ conducted a qualitative research study of the experiences of 41 nurses involved in implementing rounds in an acute care hospital in the United Kingdom (UK) to determine how caring for patients impacted their emotional and social states. Of relevance to this study is the finding that nurses often try to protect their feelings when working in critical care settings characterized by human hardship and complex care needs. This process of natural avoidance or self-protection can; however, lead to barriers in their capacity to engage in compassionate and effective communication. ${ }^{5}$ As such, there is the need to provide critical care nurses with time and space to reflect on their reactions to their stressful work environment. Too often however, this does not occur, and the nurse is left to manage a growing internal sense of fatigue. ${ }^{13}$

Due to the importance of this aspect of healthcare to critical care nurses, this integrative literature review has been conducted to shed light on the available evidence regarding the causes and management of $\mathrm{CF}$ among nurses working in these settings. The findings to emerge from the review of the literature are also used to identify the gaps in our clinical understanding of CF and the directions for future research.

The aim of this integrative literature review is to provide a critical evaluation of current empirical evidence published in peer-reviewed articles related to the prevalence, causes and outcomes of CF among critical care nurses. Focus is given particularly to the main findings reported in the studies and to their implications for nurse welfare and nursing practices.

The main research questions (RQs) for the review to answer are: 1) RQ1 = What is the prevalence of compassion fatigue among critical care nurses providing care in diverse settings? 2) RQ2 = How does compassion fatigue manifest among critical care nurses? 
3) $\mathrm{RQ3}=$ What personal and workplace strategies can help to mitigate the onset or effects of compassion fatigue among critical care nurses?

Exploring the relationship between CF and critical care nursing from these 3 areas of focus is important because the findings have the potential to improve critical care nurse wellbeing and the provision of care to patients.

Methods. An integrative literature review was selected as the most appropriate design for this study. This is a comprehensive methodological approach to reviewing the literature which allows for all types and designs of research studies to be considered for inclusion. ${ }^{14}$ The integrative literature review design is appropriate for this research study particularly because it facilitates a comprehensive research-based understanding of the phenomenon under investigation. ${ }^{15}$ Furthermore, this type of review supports the generation of generic information which leads to the identification of gaps in knowledge, areas in need of further research, and provides support for existing theories, especially in nursing. ${ }^{15}$ As such, it is useful design for a study of CF among critical care nurses as this is a developing research field which aims to better elucidate the relationships among complex patient needs, nursing practices, and the factors particular to the care setting.

A systematic and comprehensive search of the literature was completed using 3 databases with full text articles available to authors (ProQuest, ScienceDirect, CINAHL) using the keywords "compassion fatigue", "critical care nurses", "secondary trauma". A further manual search of the reference lists of included studies was also conducted. Additionally, Boolean operators were used as conjunctions to combine or exclude keywords in this search. This resulted in more focused and productive results and saved time and effort by eliminating inappropriate documents that must be scanned before discarding. The operators used in this search were as follows: AND, and OR, as well as the truncation tools of each database. Additional literature was identified through the review of the reference lists of journal articles retrieved during the review process. The search was limited to research studies undertaken from 2000 to 2018 . A time frame spanning nearly 2 decades may reasonably be considered as quite wide for a research investigation which aims to identify current prevalence rates of $\mathrm{CF}$ among critical care nurses and the strategies employed to mitigate its onset. However, it is arguably justified in this search strategy because it contributes to our understanding of how representations in the nursing literature of the concept of CF and of the strategies utilized in workplaces and by individual nurses to combat its onset have progressed overtime. Understanding these progressive aspects in turn provide a stronger foundation from which to discuss best-practice coping strategies when exploring the implications of the research findings for nursing practice.

The inclusion criteria applied to the retrieved studies were: availability of full text, peer-reviewed, electronic nursing records, description of compassion in nursing, description of factors that influence compassion in nursing, validating a tool that measures compassion, description of the health problems related to compassion, and the English or the Arabic language (as the researchers understand only Arabic and English). The exclusion criteria applied to the retrieved studies were: designs other than an original article, and a language other than those described in the inclusion criteria. Only peer-reviewed articles published in scholarly journals were considered for inclusion.

Search outcome. The selection of articles followed a 5-step process (Figure 1). Of the total 6898 studies identified by the search engines, 107 were duplicated and 5321 were not related to the search topic, directly. The abstracts of the 1470 remaining articles were given an initial review for relevance. The methodological approach and findings was examined of each of these 1470 articles for relevance to compassion fatigue in critical care nurses for further review. Finally, 70 articles were selected as they met all the search criteria of this review (Table 1). The full text of each article was then reviewed in terms of the study objective, instrument(s) used, design, main results, and conclusions. This step resulted in 15 articles remaining for possible inclusion in this review. These articles reflect real world critical care CF studies in divergent international settings.

The last step in the selection process was to exclude all non-empirical studies including previous reviews of literature due to their primary use for theoretical research and the general lack of quantitative or qualitative data provided for analysis. ${ }^{16}$ This step resulted 10 research articles for inclusion (Table 2).

Table 1 - The database search results.

\begin{tabular}{lccc}
\hline Database & $\begin{array}{c}\text { Total } \\
\text { number }\end{array}$ & $\begin{array}{c}\text { Articles } \\
\text { selected }\end{array}$ & Overlaps \\
\hline ProQuest & 6,704 & 59 & - \\
ScienceDirect & 49 & 8 & 28 \\
CINHAL & 145 & 3 & 79 \\
Total & 6,898 & 70 & 107 \\
\hline CF - compassion fatigue, BO - burnout, CS - compassion satisfaction, \\
\multicolumn{4}{c}{ STS - secondary traumatic stress } \\
\hline
\end{tabular}


Quality appraisal. Two methods were adopted in this integrative literature review related to a quality assessment of the selected studies. First, only respected and authenticated databases were utilized to perform a search for articles. Enabled this research to select only peer-reviewed articles for inclusion in the review. Second, the selected articles were evaluated manually by the first and checked by the last author using the Joanna Briggs Institute (JBI) Critical Appraisal Checklist for Analytical Cross-Sectional Studies tool. This tool was chosen based on the recognition of the Institute provides one of the best cross-sectional research quality appraisal tools available. ${ }^{17}$ The tool includes a checklist of 8 research components and a rating scale including 'Yes', 'No', 'Unsure' and 'Not Applicable' to appraise the extent to which each component reflects quality standards. The overall results suggest that the evidence quality across the 10 studies was moderate (Table 2).
Data extraction. The data extraction/analysis process in this integrative literature review aimed to reduce the collected data into a unified response to the research area of interest. ${ }^{18}$ Given the goal of the review is to investigate $\mathrm{CF}$ in terms of prevalence, causes and response strategies, and statistical tests did not feature in the analysis process. Instead, a thematic analysis of the selected articles was conducted around these areas of interest. The definition of 'theme' by Braun and Clarke ${ }^{19}$ was applied in the analysis; namely, text that captures something "important about the data in relation to the research question and represents some level of patterned response or meaning within the data set". The coding for themes then followed the 6-step process suggested by Braun and Clarke: ${ }^{19}$ familiarizing yourself with the data; generating initial descriptive codes to identify latent meaning; searching for themes

Table 2 - Summary of the articles resulting from the selection process and included in the review of literature

\begin{tabular}{|c|c|c|c|c|c|c|c|}
\hline Authors & Year & Country & Design & Sample & Instrument(s) & Main Findings & Limitations \\
\hline Cragun et $\mathrm{al}^{10}$ & 2016 & USA & $\begin{array}{l}\text { Cross sectional } \\
\text { survey method }\end{array}$ & $\begin{array}{l}105 \text { military } \\
\text { emergency officers: } \\
42 \text { nurses, } 30 \\
\text { technicians, and } 33 \\
\text { physicians. }\end{array}$ & ProQOL-5 & $\begin{array}{l}\text { Low levels of } \mathrm{CF}^{*} \text { and } \mathrm{BO}^{*} \text { were } \\
\text { reported. } \\
\text { The level of } \mathrm{CS}^{*} \text { was relatively low. } \\
\text { No association between deployment } \\
\text { and profession was statistically } \\
\text { significant. }\end{array}$ & $\begin{array}{l}\text { Single setting, convenience sample. } \\
\text { No demographic data were } \\
\text { reported. } \\
\text { No data were reported on previous } \\
\text { deployment, which might have } \\
\text { influenced the results. } \\
\text { Military officers undergo resiliency } \\
\text { training twice a year, and thus } \\
\text { could have influenced their level of } \\
\text { CF and BO. }\end{array}$ \\
\hline Kelly et $\mathrm{al}^{10}$ & 2015 & USA & $\begin{array}{l}\text { Cross-sectional } \\
\text { electronic } \\
\text { survey design }\end{array}$ & $491 \mathrm{RNs}$ & ProQOL & $\begin{array}{l}\text { Predictors of } \mathrm{BO} \text { and } \mathrm{CF} \text { include } \\
\text { lack of truthful recognition for } \\
\text { nurses. There was no significant } \\
\text { difference across nurse specialties. }\end{array}$ & $\begin{array}{l}\text { A single setting. } \\
\text { No clear connection between } \\
\text { causes of CF and } \mathrm{BO} \text { and the } \\
\text { demographic variables, except for } \\
\text { the age (years of experience). The } \\
\text { study could not identify causes of } \\
\mathrm{CF} \text { and BO. }\end{array}$ \\
\hline Hunsaker et $\mathrm{al}^{3}$ & 2015 & USA & $\begin{array}{l}\text { Descriptive } \\
\text { and predictive } \\
\text { study using } \\
\text { a survey } \\
\text { questionnaire. }\end{array}$ & $\begin{array}{l}278 \text { nurses working } \\
\text { in different } \\
\text { emergency } \\
\text { departments in the } \\
\text { USA. }\end{array}$ & ProQOL-5 & $\begin{array}{l}\text { The study reported low to average } \\
\text { levels of CF and BO. It also } \\
\text { reported average to high levels } \\
\text { of CS. The low level of manager } \\
\text { support was a significant predictor } \\
\text { of higher levels of CF and BO, and } \\
\text { a high level of manager support } \\
\text { contributed to better CS. } \\
\text { CF is less prevalent with increasing } \\
\text { age, more years in the ED, a higher } \\
\text { level of educational background, } \\
\text { and a shorter shift length. }\end{array}$ & $\begin{array}{l}\text { A cohort study that reported survey } \\
\text { findings, which lack specificity } \\
\text { and could not report factors other } \\
\text { than those present within the study } \\
\text { instrument that might have had an } \\
\text { impact on the CF and BO levels. } \\
\text { This study could not correlate } \\
\text { results to specific factors. The } \\
\text { study could not control the } \\
\text { environmental and organisational } \\
\text { factors that could have influenced } \\
\text { the results. }\end{array}$ \\
\hline Vann \& Coyer $^{28}$ & 2014 & Australia & $\begin{array}{l}\text { Cross sectional } \\
\text { survey method }\end{array}$ & $\begin{array}{l}104 \text { adult ICU } \\
\text { RNs }\end{array}$ & ProQOL-4 & $\begin{array}{l}\text { STS* and } \mathrm{BO}^{*} \text { were not prevalent } \\
\text { among participants. } \\
\text { There is a negative correlation } \\
\text { between CS, BO and STS scores. }\end{array}$ & $\begin{array}{l}\text { Single setting, convenience sample. } \\
\text { Possible contamination effect. }\end{array}$ \\
\hline $\mathrm{Kim}^{24}$ & 2013 & USA & $\begin{array}{l}\text { Cross } \\
\text { sectional, } \\
\text { descriptive- } \\
\text { explorative } \\
\text { design }\end{array}$ & $\begin{array}{l}14 \text { liver and kidney } \\
\text { transplant nurse } \\
\text { coordinators from } \\
\text { a large multiorgan } \\
\text { transplant centre }\end{array}$ & ProQOL-5 & $\begin{array}{l}\text { The study reported average level of } \\
\text { CS, an average level of BO, and an } \\
\text { average level of STS. } \\
\text { Within liver and kidney transplant } \\
\text { nurse coordinators, a statistically } \\
\text { significant relationship was found } \\
\text { between education levels and the } \\
\text { level of BO. }\end{array}$ & $\begin{array}{l}\text { Limited scope study with a low } \\
\text { number of participants might have } \\
\text { influenced the accuracy of the } \\
\text { quantitative results. } \\
\text { Single setting, purposive sample. }\end{array}$ \\
\hline
\end{tabular}


Table 2 - Summary of the articles resulting from the selection process and included in the review of literature (continued).

\begin{tabular}{|c|c|c|c|c|c|c|c|}
\hline Authors & Year & Country & Design & Sample & Instrument(s) & Main Findings & Limitations \\
\hline Sacco et al ${ }^{27}$ & 2015 & USA & $\begin{array}{l}\text { Cross-sectional } \\
\text { electronic } \\
\text { survey design }\end{array}$ & $\begin{array}{l}\text { 221Registered } \\
\text { nurses and licences } \\
\text { practical nurses, } 1 \\
\text { Hospital, } 9 \text { units. }\end{array}$ & ProQOL-5 & $\begin{array}{l}\text { Demographic factors were mostly } \\
\text { not significant in the rates of } \\
\text { compassion satisfaction except age } \\
\text { and education. Over } 50 \text { year old } \\
\text { nurses scored higher compassion } \\
\text { satisfaction scores. Nurses with } \\
\text { a bachelor degree had lower } \\
\text { compassion satisfaction scores then } \\
\text { those with lower level of education } \\
\text { and those with higher degrees. }\end{array}$ & $\begin{array}{l}\text { The single sample reflects a snap } \\
\text { shot of a period in time rather } \\
\text { than a cross-section of the nursing } \\
\text { practice over time, this may have } \\
\text { led to inadvertent "on the day' bias. } \\
\text { Lack of reliability on secondary } \\
\text { scales and burnout scale results } \\
\text { stated to be treated with caution. }\end{array}$ \\
\hline $\begin{array}{l}\text { Elkonin \& Van } \\
\text { der Vyver }^{32}\end{array}$ & 2011 & $\begin{array}{l}\text { South } \\
\text { Africa }\end{array}$ & $\begin{array}{l}\text { Cross-sectional } \\
\text { survey design }\end{array}$ & 30 ICU RNs & ProQOL-R-4 & $\begin{array}{l}\text { There is a high risk for CF, } \\
\text { a moderate risk for burnout } \\
\text { and the silencing response and } \\
\text { moderate potential for compassion } \\
\text { satisfaction. A marked negative } \\
\text { relationship was found between CS } \\
\text { and BO, and a positive relationship } \\
\text { between CF and BO. }\end{array}$ & $\begin{array}{l}\text { Three intensive care units (ICUs) } \\
\text { were included in the study. A non- } \\
\text { probability convenience sampling } \\
\text { technique. Limited number of } \\
\text { nurses was included in the study. } \\
\text { The study could not identify factors } \\
\text { leading to the CF and BO among } \\
\text { nurses. }\end{array}$ \\
\hline Von Rueden et $\mathrm{al}^{25}$ & 2010 & USA & $\begin{array}{l}\text { Cross- } \\
\text { sectional } \\
\text { survey design }\end{array}$ & $\begin{array}{l}128 \text { nurses in a } \\
\text { level I trauma } \\
\text { centre }\end{array}$ & Penn inventory & $\begin{array}{l}\text { Nine nurses }(7 \%) \text { scored } 35 \text { or } \\
\text { more, reflecting STS. } \\
\text { Those with STS had fewer years of } \\
\text { nursing experience and in trauma } \\
\text { nursing, were more likely to use } \\
\text { drugs to eliminate the psychological } \\
\text { effect of trauma and had fewer and } \\
\text { weaker support systems (such as } \\
\text { friends, families or outside groups). }\end{array}$ & $\begin{array}{l}\text { A single setting with a convenience } \\
\text { sample. sLimited scope and impact } \\
\text { of results due to limitation in data } \\
\text { collected and the single setting } \\
\text { issue. } \\
\text { The instrument measures PTSD*, } \\
\text { with limitation to CF and BO. } \\
\text { It was no clear whether the use of } \\
\text { drugs was related to PTSD or other } \\
\text { reasons. }\end{array}$ \\
\hline $\begin{array}{l}\text { Dominguez- } \\
\text { Gomez \& } \\
\text { Rutledge }^{22}\end{array}$ & 2009 & USA & $\begin{array}{l}\text { Exploratory } \\
\text { comparative } \\
\text { design }\end{array}$ & $\begin{array}{l}67 \text { emergency } \\
\text { nurses from } 3 \\
\text { general community } \\
\text { hospitals }\end{array}$ & STS survey & $\begin{array}{l}\text { Nurses reported having arousal } \\
\text { symptoms (irritability reported } \\
\text { by } 54 \% \text { of nurses), followed by } \\
\text { avoidance, and intrusion symptoms } \\
\text { (intrusive thoughts about patients). } \\
\text { Most nurses reported at least one } \\
\text { symptom in the past week. } \\
\text { Approximately, 33\% met all criteria } \\
\text { of STS. } \\
\text { Participation in stress management } \\
\text { activities was associated with less } \\
\text { prevalence of STS symptoms. }\end{array}$ & $\begin{array}{l}\text { STS survey reliability has not been } \\
\text { reported. STS survey scope ids } \\
\text { limited to PTSD symptoms. } \\
\text { Convenience sampling, a single } \\
\text { geographical location, and self- } \\
\text { administered questionnaire might } \\
\text { have reflected more favourable } \\
\text { results to the participants. }\end{array}$ \\
\hline Kenny $\&$ Hull $^{21}$ & 2008 & USA & $\begin{array}{l}\text { Cross- } \\
\text { sectional } \\
\text { survey design }\end{array}$ & $\begin{array}{l}18 \text { nurses working } \\
\text { in two U.S. } \\
\text { military medical } \\
\text { treatment facilities } \\
\text { before and after } \\
\text { the beginning } \\
\text { of the wars in } \\
\text { Iraq (Operation } \\
\text { Iraqi Freedom } \\
\text { and Afghanistan- } \\
\text { Operation } \\
\text { EnduringFreedom. }\end{array}$ & $\begin{array}{l}\text { Stressors } \\
\text { and coping } \\
\text { mechanisms } \\
\text { of ICU Nurses } \\
\text { Before and After } \\
\text { the operation" } \\
\text { Survey }\end{array}$ & $\begin{array}{l}\text { High levels of stress and CF has } \\
\text { been reported by nurses. } \\
\text { Sources of stress include (young) } \\
\text { age of the soldiers coupled } \\
\text { with the severity of their injuries, } \\
\text { having to deal with } \\
\text { (too demanding) family members, } \\
\text { and the high workload with a } \\
\text { sustained shortage of qualified } \\
\text { nurses. Coping mechanisms include } \\
\text { ventilating and debriefing with } \\
\text { other co-workers, hobbies, trying } \\
\text { to understand their situation, } \\
\text { and activities within their social } \\
\text { networks. }\end{array}$ & $\begin{array}{l}\text { Low response rate }(18 \%) \text { and low } \\
\text { number of participants. } \\
\text { Self-administered questionnaire } \\
\text { might have reported favourable } \\
\text { results by the participants. }\end{array}$ \\
\hline
\end{tabular}


relevant to the literature review aims; reviewing selected themes for convergences; producing the final thematic classifications.

Results. An initial review of the 10 studies included in this review primarily focused on the factors that potentially contributed to the onset of CF among critical care nurses and the consequences associated with their CF experience. Across the general 'causes of $\mathrm{CF}$ ' and 'consequences of CF' research domains covered by the studies, 3 broad themes were identified: 1) the prevalence of $\mathrm{CF}$ among critical care nurses; 2) work environment and nurse demographics (namely age and years of experience) predictors of CF; and 3) the factors mitigating $\mathrm{CF}$ affects among critical nurse including coping strategies. As revealed when determining these thematic classifications, there was overlap in the key focus areas of some studies (Hunsaker et $\mathrm{al}^{3}$ studied both the factors contributing to, and the consequences of, $\mathrm{CF}$ among ED nurses). In addition, several studies focused on the development of CF among nurses in relation to specific practice contexts, including military emergency medicine settings, ${ }^{10}$ acute care settings, ${ }^{4}$ ED settings, ${ }^{3}$ exposure to traumatic events, ${ }^{28}$ and general critical care environments. ${ }^{21}$ Notably, the diversity of care settings also provided a diversity of patient 'types' receiving care from the nurses including military personnel, ${ }^{10,21}$ trauma patients, ${ }^{28}$ and the general public. ${ }^{3,4,22}$

The following section synthesizes the results from the integrative review by focusing on points of convergence and divergence in the research findings related to the 3 main themes. This helps to support the discussion of new ideas and areas for further research on $\mathrm{CF}$ as an issue for nurses in critical care areas.

Prevalence of CF among nurses. The research findings reporting on the prevalence of CF among critical care nurses (RQ1) is inconsistent. For instance, Hunsaker et $\mathrm{al}^{3}$ sought to determine the prevalence of CF among ED nurses $(n=278)$ in the United States. The authors reported that almost $66 \%$ of ED nurses had low-level of CF. Similarly, Dominguez-Gomez \& Rutledge ${ }^{22}$ examined the presence of variables associated with CF; namely, arousal (irritability) symptoms, avoidance symptoms, and intrusion symptoms among emergency nurses $(n=67)$ working in general hospitals in the United States. The authors reported that most nurses $(85 \%)$ experienced at least one symptom of CF during the previous week and that it contributed to emotional exhaustion and job separation.

In contrast, Vann and Coyer ${ }^{28}$ surveyed registered nurses $(\mathrm{n}=174)$ working in an ICU at a tertiary referral hospital in Queensland for their level of CF. The authors reported that the nurses achieved on average 36.13 out of 50 for their compassion satisfaction score indicating low level prevalence of CF among the ICU nurses. Lastly, Elkonin and Van der Vyver ${ }^{23}$ studied work-related CF among intensive care nurses $(n=75)$ working in private health care settings in the United Kingdom. In contrast to the moderate ${ }^{22}$ to high $^{23} \mathrm{CF}$ prevalence rates among critical care nurses, Elkonin and Van der $V_{y v e r}{ }^{23}$ reported the prevalence of CF among their nurses participants was low (around 25\%) based on indications from most nurses $(73.34 \%, \mathrm{n}=22)$ that their potential for experiencing compassion satisfaction was moderate to high.

Work-related factors and nurse characteristics as predictors to $C F$. In terms of the relationship between work-related factors and the development of $\mathrm{CF}$ among critical care nurses (RQ2), Hunsaker et $\mathrm{al}^{3}$ found that hours worked per week, and lack of access to managerial support were significantly associated with CF prevalence among ED nurses. Similarly, Kenny and Hull $^{21}$ identified the work-related stressor leading to CF commonly experienced by nurses caring for soldiers with multiple severe, and life-threatening injuries. The authors reported the anxieties demonstrated by the soldiers in response to their injuries, feelings of powerless to provide any real likelihood of positive change to patients and family members, and the complexity of patients' care needs were the main causes of CF among this cohort.

Furthermore, Cragun et $\mathrm{al}^{10}$ explored the relationship between exposure to stressful workplace situations and the development of CF in their study of the impact of combat deployment on CF among 105 military health care professionals representing different scopes of practice who had been or who had not been deployed. From a sample including 42 nurses ( $\mathrm{n}=20$ previously deployed), 30 technicians ( $\mathrm{n}=11$ previously deployed), and 33 doctors ( $n=16$ previously deployed), the authors found no statistically significant differences in the level of CF between previously deployed healthcare professionals compared to those not previously deployed.

Regarding the relationship between nurse demographic characteristics and CF, Hunsaker et $\mathrm{al}^{3}$ focused on the age, years of experience and educational level of the ED nurses. The authors found that higher education level was associated with lower level CF among ED nurses. Indeed, education level emerged in other studies as a factor mitigating the effects of $\mathrm{CF}$ for critical care nurses. Kim's ${ }^{24}$ study on the level of compassion satisfaction and CF among 14 nurses working in a large multi-organ transplant center 
reported that the level of CF was average, but that a statistically significant relationship existed between was the education levels of unit transplant nurses and the level of CF they experienced.

In terms of age and years of experience as a predictor of CF, Hunsaker et $\mathrm{al}^{3}$ found that older nurses scored lower on the presence of CF compared to younger nurses who, on average recorded higher CF scores. Notably, this finding is in contrast to that reported by Kelly et al. ${ }^{4}$ Kelly et al ${ }^{4}$ examined the factors impacting $\mathrm{CF}$ in acute care nurses $(\mathrm{n}=491)$ working in diverse inpatient specialty areas (intensive care, oncology, neurology) in the United States. The author reported older-age (ages 50-65 years) as more significant predictor of CF compared to younger age (21-33 years). In addition, they found CF as more strongly correlated among nurses with more years of experience compared to nurses with fewer years of experience. In terms of the work environment, Kelly et $\mathrm{al}^{4}$ found no significant differences in CF among acute care nurses across nurse specialties, units, or departments.

Adding to our understanding of the potential relationship between certain nurse demographic characteristics and CF experiences is the Von Reuden et $\mathrm{a}^{25}$ study. Specifically, the authors administered a behavioural survey and Penn Inventory to measure the presence of CF among nurses $(n=262)$ working in a level-1 trauma centre. Hunsaker et $\mathrm{al}^{3}{ }^{3}$ reported that the presence of CF was higher among nurses with fewer years of experience and with limited access to managerial support. Von Reuden et $\mathrm{al}^{25}$ and Sodeke-Gregson et $\mathrm{al}^{26}$ also found that younger age and low-level management support were a strong predictor for CF among therapists $(\mathrm{n}=253)$ working with trauma patients in the United Kingdom. The authors also reported that the highest CF risk for the trauma therapists was to experience secondary traumatic stress.

Factors mitigating the effects of CF among critical care nurses. As reported above, several studies ${ }^{3,25}$ identified a range of individual or institution related factors can potentially mitigate the effects of CF among crucial care nurses including access to support from management, and level of education. ${ }^{24,27}$ Furthermore, Elkonin and Van der $V_{y v e r}{ }^{23}$ reported an association between critical care nurses' silencing responses to workplace stressor and the increased potential for experiences of CF. The silencing response is described by the authors as "the inability of caregivers to pay attention to the stories or experiences of their patients and the tendency to direct the conversation rather to less distressing material". ${ }^{23}$ In addition, Kenny and Hull ${ }^{21}$ briefly explored the coping strategies employed by the nurses to manage their work-related stressors. According to the authors, speaking to others about one's individual experiences of the impact of the workplace stressors is crucial, along with maintaining professional boundaries with patients.

Discussion. This integrative literature review of 10 cross-sectional empirical studies was undertaken to broaden our academic and practice understanding of the prevalence of $\mathrm{CF}$ among critical care nurses providing care in diverse settings (RQ1), the way in which CF manifests among critical care nurses (RQ2), and the personal and workplace strategies utilised to mitigate the effects of CF (RQ3). Compassion fatigue is conceptualized as occurring in critical care settings when the nurse becomes preoccupied with internalizing the trauma and emotional stresses surrounding patients in their care, creating secondary traumatic stress. ${ }^{23,24}$ As evidenced in the following discussion, the varied research findings reported and discussed in this integrative review of studies points to the complex nature of $\mathrm{CF}$ and its management.

Prevalence of CF among critical care nurses. In terms of RQ1, the finding in this review that there is inconsistency in the prevalence rates of CF between nurses in diverse critical care settings reported in crosssectional studies is reflected in the broader literature.

According to Van Mol et $\mathrm{al}^{20}$ appropriate measures of CF among critical care nurses "remains open for discussion" given the diverse ways it can manifest in nurses and the fact that its expressions are not always easy to identify. The prevalence of CF among the nurses investigated in the selected studies was generally measured according to the same 4 outcomes: the nurses' indications of sadness and grief in relation to patient conditions, avoidance of care towards patients, detachment from colleagues and patients, and decreased social interactions with others in the workplace. ${ }^{4,24,26} \mathrm{It}$ remains difficult to determine the true extent to which these outcomes manifest as $\mathrm{CF}^{4,26}$ given the diverse ways it can find expression. This is because exposure to the same risks of psychological distress when providing care to patients can impact critical care nurses in diverse and unique ways based on the temperament of the nurse and the work conditions when seeking to measure CF. ${ }^{30}$

Causes of CF among critical care nurses. The focus in RQ2 on the causes of CF among critical care nurses is intended to provide insights into the nature of the relationship between nurse demographic characteristics and workplace characteristics as contributor to CF. This review found that multiple and diverse factors may contribute to the onset of CF including the personal characteristics and attributes of the critical 
care nurse, previous exposure to trauma and complex patient care scenarios, years of experience working in critical care settings and the work environment more broadly. 3,25,26 The association between the identified nurse demographic characteristics and CF onset is perhaps not surprising. The broader research literature commonly points the ways in which the age, years of nursing experience, and personal attributes including 'resilience' and 'high self-expectations' can influence diverse care-related outcomes for nurses in critical care settings. ${ }^{29}$ These outcomes include moral distress, ${ }^{31}$ burn out, ${ }^{32}$ perceived poor job satisfaction, ${ }^{33}$ and all factors associated with CF. Indeed, Craigie et $\mathrm{al}^{2}$ refer to the 'costs of caring' and to the occupational hazard of working in critical care settings. In turn, the review finding suggests that the demographic characteristics of the critical care nurse can influence their capacity to cover the 'costs' of continued exposure to patient mortality and suffering, and high-pressure working conditions.

This paper also found that the constant demands on nurses' emotional reserves due to high patient mortality rates and feelings of being unable to provide adequate relief to suffering patients contributed to compassion exhaustion. This outcome may be explained by drawing on reports in the literature that difficult working conditions including work overload and complex patient demands can lead some nurses to lose their sense of purpose and understanding of the meaning of compassionate and dignified care. ${ }^{34}$

Furthermore, the finding reported above regarding the challenging work conditions (such as poor management support or inadequate training) can exacerbate distressing patient situations for critical care nurses leading to $\mathrm{CF}$ is supported in the wider research literature. For instance, a systematic review by Adriaenssens et $\mathrm{al}^{35}$ found that work environment factors including exposure to traumatic events, job characteristics (workload, colleague support) and organizational variables (staffing or communication and collaboration issues) contributed to deterioration in psychological wellbeing among nurses.

Factors and coping strategies to reduce the risk of compassion fatigue. The results for the relationships between nurse demographic characteristics, workplace characteristics, and the onset of CF for critical care nurses reported above provide context to the findings related to RQ3. This question focused on the factors that reduce the risk of $\mathrm{CF}$ or which assist nurses to manage their experiences of CF. The main finding in this regard was that both personal (years of work experience, education level, personality attributes) and workplace factors (management support and education and training programs) can impact nurses' experiences of CF.

At the individual level, the broader literature identifies ongoing learning, the adoption of self-care strategies, and the enforcement of suitable emotional boundaries as 3 potential self-directed approaches for critical care nurses to reduce the risk of $\mathrm{CF}^{30}$ The focus on these approaches appears to reinforce the importance of nurse self-awareness of the impact of workplace conditions on personal wellbeing combined with a proactive attitude towards achieving a satisfying work-life balance. ${ }^{30}$

At the organizational level, the findings reported by Hunsaker et $\mathrm{al}^{3}$ showing an association between access to manager support and experiences of CF among nurses also point to the importance of formal programs and initiatives for the prevention and management of CF. As discussed in the broader literature, there is importance placed on workplace education and training provisions to nurses on how to identify the early symptoms of CF such as emotional detachment and care avoidance. ${ }^{30,36}$ However, these suggestions of course only address the nurses' personal response to the CF experience. ${ }^{36}$ Equal importance must arguably be placed on the workplace response to reduce the risk of CF among nursing staff. Some of the selected cross-sectional studies ${ }^{3,25}$ emphasized the need for positive and supportive practice environments and adequate manager support to limit the onset of CF among nurses. However, the depth of detail to which these institutionally driven strategies are discussed in the studies is limited. Indeed, none of the studies provided clear descriptions of what constitutes good supervision in critical care settings.

According to Etherington, ${ }^{37}$ for CF-related supervision to be effective it should attend to the inter relationships among the trauma, the patient, the nurse, the therapeutic relationship and the dynamics within the workplace. Any attempt to address all these aspects for the prevention and management of CF among nurses must arguably rely heavily on effective collegial and leadership support mechanisms. A recent study by Berg et $\mathrm{a}^{38}$ provides a useful 8 -step process for managers in this regard: 1) ensure CF is acknowledged and accepted as a reality; 2) provide education to staff on how to recognize CF signs and symptoms; 3) facilitate team-based stresscoping skills (mindfulness, self-soothing) development; 4) ensure managers openly demonstrate social support; 5) normalize the workplace discourse around coping in response to challenges; 6 ) ensure managers are proactive 
in high-crisis interventions; 7) place emphasis on the positive aspects of patient care; and 8) seek regular feedback from staff on their CF experiences and coping strategies.

Practice implications CF among critical care nurses. The finding in this review of 10 cross-sectional research studies of CF among critical care nurses of an inconsistency in reported prevalence has implications for the nature of the culture of the workplace in relation to collaborative and supportive care. The reasons for this inconsistency were nurse reluctance to openly acknowledge CF experiences in combination with our general lack of understanding of how CF may manifest. As alluded to above, the extent to the organizational culture values open debriefing by nurses regarding taxing care experiences or endorse and supports education and training on coping strategies is critical to establishing the types of support systems needed to encourage nurses to share CF experiences and to identify signs of CF in colleagues. ${ }^{27}$ Moreover, a workplace culture that reflects the 8 elements for effective organizational responses to CF by Berg et $\mathrm{al}^{37}$ is recommended.

The second practice implication associated with the findings reported in this review relate to self-assessment practices of critical care nurses to identify and respond to the signs and symptoms of CF. The broader literature alludes to the greater need for nurses to be educated in appropriate self-assessment processes to identify CF indicators and to develop effective recovery plans. As stated by Poncet et al, ${ }^{39}$ failure to acknowledge and respond to the pressures of caring can result in the depersonalization of patients by nurses and a lost sense of empowerment in the practices of care. In turn, the extent to which nurses are supported in the processes of self-assessment for CF can significantly influence their capacity to build the physical and emotional fortitude required to avert $\mathrm{CF}^{39}$

Notably, effective self-assessment strategies by critical care nurse to the impact of CF on their personal lives and professional practices generally include a focus on interpersonal and communication skills. ${ }^{40}$ Part of the self-assessment process is gauging one's emotional state and responses relative to others in the care setting. ${ }^{40}$ The implication for nurses in critical care settings is that they engage in opportunities to share experiences of the care demands of the setting and to explore coping strategies with colleagues in the workplace. ${ }^{10}$

Implications for further research. The findings reported in the selected cross-sectional studies of CF imply the importance of gaining a better understanding of the optimal training and support provisions to nurses to avoid and/or manage CF. In turn, there are several opportunities for further empirical research of the effectiveness of self-management and institutionalbased strategies to assist critical care nurses to reduce CF. Our clinical practice and academic understanding of CF and its management would also benefit from further research of the types of strategic workplace initiatives required to best support critical care nurses to achieve a work-life balance. The findings from such research may enable health organizations to better support nurses assert their personal needs and values while providing compassionate and empathetic care aimed at optimizing outcomes for patients.

This review also asserts the importance of further studies of effective CF coping strategies for nurses. Acknowledging the potential for critical care nurses to experience CF due to working conditions in combination with education and training on coping techniques is integral to reducing the likelihood of CF onset and to improving patient care. ${ }^{4}$ As such, research investigating how the care environment can best be designed to assist nurses to understand and respond to their emotional experience to the provision of care may help to reduce the development of CF among these nurses.

Lastly, the cross-sectional studies included in this review all sought to collect quantitative data related to nurses' CF experiences using the Professional Quality of Life Scale (ProQOL41) instrument except for Kenny and Hull ${ }^{21}$ and Dominguez-Gomez and Rutledge. ${ }^{22}$ Given CF is a highly subjective experience for critical care nurses, valuable research insights could be gleaned from studies employing qualitative research paradigms. Indeed, qualitative studies of this phenomenon can assist researchers and clinical care nurses to better understand the manifestation and impacts of CF by accessing nurses' interpretations of their CF experiences. Qualitative data of this type can be combined with quantitative data sets to provide a more comprehensive understanding of the CF phenomenon through consideration of both the statistical and interpretive representations of CF in critical care settings.

In conclusion, the results from the literature review demonstrate that research studies have been conducted on various aspects of $\mathrm{CF}$ and the coping strategies employed by nurses who experience this phenomenon. The key findings reported and discussed above included the way in which the nature of the therapeutic relationship and the specialised type of care allows for the development of close relationships between nurses and their patients. As such, the risk of CF is higher 
among critical care nurses than nurses working in noncritical care settings due to the critical nature of patients' conditions and the closeness with which the nurses work with patients and family members. Given the onset of CF may include indicators including clinical and medication errors, higher rates of sick leave, and nosocomial infections, it is of some concern that the international literature is replete with studies examining CF coping strategies. This integrative review therefore asserts the importance of further studies of CF and the coping strategies employed by nurses to reflect on their experiences to inform future strategies and policy initiatives to improve compassion satisfaction.

\section{References}

1. Goetz J, Keltner D, Simon-Thomas E. Compassion: An evolutionary analysis and empirical review. Psychol Bull 2010; 136: 351-374.

2. Craigie M, Osseiran-Moisson R, Hemsworth D, Aoun S, Francis K, Brown J, et al. The influence of trait-negative affect and compassion satisfaction on compassion fatigue in Australian nurses. Psychol Trauma 2016; 8: 88-97.

3. Hunsaker S, Chen HC, Maughan D, Heaston S. Factors that influence the development of compassion fatigue, burnout, and compassion satisfaction in emergency department nurses. J Nurs Scholarsh 2015; 47: 186-194.

4. Kelly L, Runge J, Spencer C. Predictors of compassion fatigue and compassion satisfaction in acute care nurses. J Nurs Scholarsh 2015; 47: 522-528.

5. Duarte J, Pinto-Gouveia J, Cruz B. Relationships between nurses' empathy, self-compassion and dimensions of professional quality of life: A cross-sectional study. Int J Nurs Stud 2016; 60: $1-11$.

6. Alameddine M, Dainty KN, Deber R, Sibbald WJ. The intensive care unit work environment: Current challenges and recommendations for the future. J Crit Care 2009; 24: 243-248.

7. Todaro-Franceschi V. Critical care nurses' perceptions of preparedness and ability to care for the dying and their professional quality of life. Dimens Crit Care Nurs 2013; 32: 184-190.

8. Aycock N, Boyle D. Interventions to manage compassion fatigue in oncology nursing. Clin J Oncol Nurs 2009; 13: 183-191.

9. Chen Y, Ben KS, Fortson BL, Lewis J. Differential dimensions of death anxiety in nursing students with and without nursing experience. Death Stud 2006; 30: 919-929.

10. Cragun JN, April MD, Thaxton RE. The impact of combat deployment on health care provider burnout in a military emergency department: A cross-sectional professional quality of life scale v survey study. Mil Med 2016; 181: 730-734.

11. Maben J. Support staff to support patients. The Health Service Journal 2013; 123: 20.

12. Goodrich J. Supporting hospital staff to provide compassionate care: Do Schwartz Center Rounds work in English hospitals? J $R$ Soc Med 2012; 105: 117-122.
13. Cieslak R, Shoji K, Douglas A, Melville E, Luszczynska A, Benight CC. A meta-analysis of the relationship between job burnout and secondary traumatic stress among workers with indirect exposure to trauma. Psychol Serv 2014; 11: 75-86.

14. Whittemore R, Knafl K. The integrative review: Updated methodology. J Adv Nurs 2005; 52: 546-553.

15. Onwuegbuzie AJ, Frels R. Seven Steps to a Comprehensive Literature Review: A multimodal and cultural approach. London (UK): CPI Group: 2016.

16. Campbell DT, Stanley JC. Experimental and quasi-experimental designs for research. Ravenio Books: 2015.

17. Zeng X, Zhang Y, Kwong JS, Zhang C, Li S, Sun F, et al. The methodological quality assessment tools for preclinical and clinical studies, systematic review and meta analysis, and clinical practice guideline: A systematic review. J Evid Based Med 2015; 8: 2-10.

18. Russell, C. L. An overview of the integrative research review. Prog Transplant 2005; 15: 8-13.

19. Braun V, Clarke V. Using thematic analysis in psychology. Qualitative Research in Psychology 2006; 3: 77-101.

20. Van Mol MMC, Kompanje EJO, Benoit DD, Bakker J, Nijkamp MJ. The prevalence of compassion fatigue and burnout among healthcare professionals in intensive care units: A systematic review. PLoS ONE 2015; 10: 1-14. e0136955.

21. Kenny DJ, Hull MS. Critical care nurses' experiences caring for the casualties of war evacuated from the front line: Lessons learned, and needs identified. Crit Care Nurs Clin North Am 2008; 20: 41-49.

22. Dominguez-Gomez E, Rutledge DN. Prevalence of secondary traumatic stress among emergency nurses. J Emerg Nurs 2009; 35: 199-204.

23. Elkonin D, Van der Vyver, Positive and negative emotional responses to work-related trauma of intensive care nurses in private health care facilities. Health SA Gesondheid 2011; 16 : (1).

24. Kim, S. Compassion fatigue in liver and kidney transplant nurse coordinators: A descriptive research study. Prog Transplant 2013; 23: 329-335.

25. Von Rueden KT, Hinderer K, Murray M, Logan T, Kramer B, Gilmore R, et al. Secondary traumatic stress in trauma nurses: Prevalence and exposure, coping, and personal/environmental characteristics. J Trauma Nurs 2010; 17: 191-200.

26. Sodeke-Gregson EA, Holttum S, Billings J. Compassion satisfaction, burnout, and secondary traumatic stress in UK therapists who work with adult trauma clients. Eur J Psychotraumatol 2013; 4: 21869.

27. Sacco TL, Ciurzynski SM, Harvey ME, Ingersoll GL. Compassion satisfaction and compassion fatigue among critical care nurses. Crit Care Nurse 2015; 35: 32-42.

28. Vann A, Coyer F. Exploring compassion fatigue: How does compassion fatigue affect the intensive carenurse? Aust Crit Care 2014; 27: 46.

29. Berger J, Polivka B, Smoot EA, Owens H. Compassion fatigue in pediatric nurses. J Pediatr Nurs 2015; 30: e11-e17.

30. Lombardo B, Eyre C. Compassion fatigue: A nurse's primer. Online Journal of Issues in Nursing 2011; 16: 1-12.

31. Dodek PM, Wong H, Norena M, Ayas N, Reynolds SC, Keenan SP, et al. Moral distress in intensive care unit professionals is associated with profession, age, and years of experience.J Crit Care 2016; 31: 178-182. 
32. Hayes B, Douglas C, Bonner A. Work environment, job satisfaction, stress and burnout among haemodialysis nurses. $J$ Nurs Manag 2015; 23: 588-598.

33. Rushton CH, Batcheller J, Schroeder K, Donohue P. Burnout and resilience among nurses practicing in high-intensity settings. Am J Crit Care 2015; 24: 412-420.

34. Osborn R, Moulds D, Schneider EC, Doty MM, Squires D, Sarnak DO. Primary care physicians in ten countries report challenges caring for patients with complex health needs. Health Aff (Millwood) 2015; 34: 2104-2112.

35. Adriaenssens J, De Gucht V, Maes S. Determinants and prevalence of burnout in emergency nurses: A systematic review of 25 years of research. Int J Nurs Stud 2015; 52: 649-661.

36. Hendrix CC, Bailey DE, Steinhauser KE, Olsen MK, Stechuchak KM, Lowman SG, et al. Effects of enhanced caregiver training program on cancer caregiver's self-efficacy, preparedness, and psychological well-being. Support Care Cancer 2016; 24: 327-336.
37. Etherington K. Supervising helpers who work with the trauma of sexual abuse. British Journal of Guidance \& Counselling 2009; 37: 179-194.

38. Berg GM, Harshbarger JL, Ahers-Schmidt CR, Lippoldt D. Exposing compassion fatigue and burnout syndrome in trauma team: A qualitative study. J Trauma Nurs 2016; 23: 3-10.

39. Poncet MC., Toullic P, Papazian L, Kentish-Barnes N, Timsit JF, Pochard F, et al. Burnout syndrome in critical care nursing staff. Am J Respir Crit Care Med 2007; 175: 698-704.

40. Meichenbaum D. Stress inoculation training: A preventative and treatment approach. In: The evolution of cognitive behavior therapy. New York (NY): Routledge: 2017. p. 117-140.

41. Stamm BH. The Concise ProQOL Manual. Pocatello (ID): ProQOL.org; 2010. 